\title{
Why students tend to compare themselves with each other? The role of mattering and unconditional self-acceptance
}

\author{
Shien-Yi Kam, Kususanto Ditto Prihadi \\ Department of Psychology, HELP University, Kuala Lumpur, Malaysia
}

\begin{tabular}{l} 
Article Info \\
\hline Article history: \\
Received Nov 26, 2020 \\
Revised Mar 29, 2021 \\
Accepted Apr 15, 2021 \\
\hline
\end{tabular}

Keywords:

Mattering

Social comparison

Unconditional self-acceptance

\begin{abstract}
Previous studies suggested that university students who are not able to accept themselves tend to develop negative tendency to compare themselves with each other. This study aimed to investigate the role of unconditional selfacceptance (USA) in explaining the association between mattering and social comparison among Malaysian undergraduate students. Three hundred and seventy undergraduate students were recruited and asked to complete an online version of Unconditional Self-Acceptance questionnaire, IowaNetherlands Comparison Orientation Measure and University Mattering Scale. Data analysis was conducted by employing Bootstrap Method with 95\% confidence interval and 5000 sampling. The result showed that USA partially mediated the relationship between mattering and social comparison. Mattering and USA were identified as robust protective factors of social comparison among university students.
\end{abstract}

This is an open access article under the CC BY-SA license.

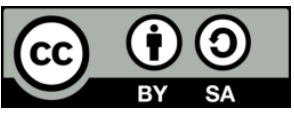

\section{Corresponding Author:}

Kususanto Ditto Prihadi

Department of Psychology

HELP University

Persiaran Cakerawala, Section U4, Shah Alam, Malaysia

Email: prihadi.k@help.edu.my

\section{INTRODUCTION}

The main focus of this current study is to examine whether unconditional self-acceptance can explain the protective property of mattering on social comparison among undergraduate students in Malaysia. Social comparison tendency became our main context, because social comparison theory, suggested that it is our primary motive to learn and compare ourselves with those around us to define the self [1]; nevertheless, the current trend indicates that when university students have the tendency to compare themselves with others, in terms of academic achievement [2], physical appearance [3], or general life satisfaction [4], [5] they would likely to develop emotional difficulties and mental health issues, such as uncontrolled anger and depression [6], [7], especially if they lack of ability to accept themselves unconditionally. In other words, abilities to unconditionally accept oneself keep the levels of happiness and well-being, positive self-esteem and optimism, as well as protect individuals from depression and anxiety [8], [9]. Moreover, individuals aged between 18-25 years were in the mist of identity exploration, possibilities and instability, which push them to develop higher tendency to compare themselves to others more than any other age group [10]. Students' general psychological well-being has become an emphasis in the studies of the last decade, especially during the uncertain period related to the current global pandemic [11], [12]. The last thing the society needs is to have the next generation of workforce suffering from the tendency to compare oneself to others, which might lead to the aforementioned negative issues. Therefore, in this current paper, we discuss how two interpersonal factors, namely mattering and unconditional self-acceptance (USA) play their protective roles against the social comparison tendency. 
Studies on USA in the last two decades have established that it predicts many other variables related to the intrapersonal features, such as irrational beliefs [13], perfectionism on interpersonal competence [14], and mindfulness [15]. Related to interpersonal relationship, USA was found to be related to social comparison [16], which eventually led to other interpersonal elements, such as guilt, regret and blame [17], lower levels of happiness [18] and among the population of university students, the feeling of academic inferiority [19]. Because the ability to accept oneself holds significant role in protecting our students from the risks of mental health, it is important to review how such an ability was developed.

USA was theorized by Ellis when determining the element of 'dysfunctional self-rating process' in self-esteem, and defined USA as "the individual fully and unconditionally accepts himself whether or not he behaves intelligently, correctly, or competently and whether or not other people approve, respect, or love him" [20]. While the constructs of self-esteem and USA might overlap, past studies noted that there was a key distinction between self-esteem and USA; self-esteem positively correlated with narcissism, whereas USA and narcissism were uncorrelated [8]. The uncorrelation between USA and narcissism brought us to further idea that USA tend to be more interpersonal than intrapersonal; for instance, when we feel we matter to others, we tend to develop higher unconditional self-acceptance (USA) and lower self-criticism [21].

The relationship between the sense of mattering and USA lies on the fact that both of them require social feedback to develop; for instance, mattering also refers to the sense that our presence makes difference in other people's lives and that we are significant to the world around us [22]. Such belief will not be able to be developed without social feedback from the people around us that give us information how much we matter to them. Moreover, each construct of mattering is related to how we believe others perceive us, such as how much they aware of our presence, how much they rely on us, and their 'ego-extension', that refers to how similar their reaction to ours when something happens to us [22]-[24].

Social comparison theory [1] explains that we will not be able to develop the concept of who we are before we compare ourselves with others. Some individuals even need to keep comparing themselves to others more frequently because they could not accept the 'results' of their previous social comparison [25]. Therefore, individuals who are able to accept how they conceptualize themselves, tend to have lower tendency to compare themselves to others [13], because they also tend to show less need for approval, and therefore less susceptible of negative evaluations or critics [26]. In line with that, one construct of social comparison, ability, was inversely correlated to individual's self-acceptance [27]. Similar to USA, mattering was also reported to be positively associated with social comparison [28] the tendency of social comparison may be predicted by how they perceived themselves mattered for others, and in either ways, will eventually altered their self-evaluation and self-concept.

While both mattering and USA similarly predict the tendency of social comparison, the link between the two predictors was also reported by numerous previous studies. For instance, it was reported that university students who believe they matter to others tend to be able to accept who they are even in the face of disappointment [21]. Furthermore, mattering was reported to be the significant predictor of USA especially in a school context [29]. In other words, when individuals believe they matter to others, they tend to develop higher USA, where they will accept themselves as who they are unconditionally, thus negative feedback will not affect their self-evaluation and self-improvement. This was also in line with the study explaining that perceived positive relation with others and self-acceptance is related, indicating that the sense of interpersonal mattering elevates one's perceptions of harmonious relationship with others [30].

The aforementioned link between mattering and USA brought us to our hypothesis that USA might be able to mediate the link between mattering and social comparison tendency. In other words, we hypothesized that the more students believe that they matter much to others, the more they will be able accept themselves unconditionally, which in turn, reduce their tendency to compare themselves with others. The motivation behind our study was to obtain better knowledge whether improving students' sense of mattering might help them to accept themselves and eventually reduce the negative effect of social comparison such as depressive symptoms and low academic self-efficacy.

\section{RESEARCH METHOD}

A priori power analysis via $G$ Power was used to determine the sample size for this study. The power analysis was conducted with medium effect size and a power of $.95\left(f^{2}=0.15, \alpha=.95\right)$. By these criteria, the desired total sample was 107 participants; nevertheless, in order to be able to represent larger population, 370 university students between 18 and 30 years of age were recruited to participate in this current study to match the sample size suggested by the Krejcie and Morgan's Table [31]. Due to global pandemic, all of the participants studied online from home at the time when data was collected. A Google form containing an informed consent form, demographic questionnaire, and all the scales to gauge the variables was accessible through a link that was disseminated through our social media such as Facebook, Instagram, LinkedIn, 
WhatsApp, WeChat, Telegram, as well as emails after this study was approved by the Ethic Review Boards from Department of Psychology, HELP University, Malaysia. These participants were voluntarily access the link to our informed consent form, where they were informed that they were allowed to leave the survey at any time they felt any discomfort, demographic questionnaire page, followed by the scales we utilized to measure each of our variables.

Mattering was measured by utilizing University Mattering Scale (UMS) [23]. Social comparison was gauged by employing Iowa-Netherlands Comparison Orientation Measure (INCOM) [25], and Unconditional Self-Acceptance Questionnaire (USAQ) [8] was utilized to collect data on USA. The analyses were conducted by utilizing PROCESS Macro model 4 because we opted to conduct the analyses with Bootstrap method in order to see the significance of the mediation effects. Multiple linear regressions were not chosen due to its inability to report the significance of the mediator without employing other statistical analysis engine such as Sobel Test. The bootstrap was conducted with 5000 samplings at $95 \%$ confidence interval.

\section{RESULTS AND DISCUSSSION}

\subsection{Descriptive statistics}

Bootstrap Method was considered a robust method to measure directional relationship among variables regardless the normality of the data. Nevertheless, assumption tests were still conducted in order to describe our data. The average score for mattering was $86.35(M=86.35, S D=10.98)$, while the average score for USA was $77.27(M=77.27, S D=10.52)$. For social comparison tendency, the average score was 39.82 $(M=39.82, S D=5.98)$. The assumption of normality was met for all variables, social comparison (ShapiroWilk (142)=.98, p=.098), unconditional self-acceptance (Shapiro-Wilk (142)=.99, p=.248) and mattering (Shapiro-Wilk $(142)=.98, \mathrm{p}=.086)$. The analysis data showed that the assumption of collinearity indicated that multicollinearity was not a concern (USA, Tolerance=.93, VIF=1.07; mattering, Tolerance $=.93$, $\mathrm{VIF}=1.07)$, as the value of variance-inflation factor (VIF) was less than 10 and the tolerance value was more than 0.2. The normal P-P plot of regression standardized residuals has indicated that the data contained approximately normally distributed errors, which showed that the points were not completely but closely on the line. The scatterplot of standardized residuals in Figure 1 shows that the data met the assumptions of homoscedasticity.

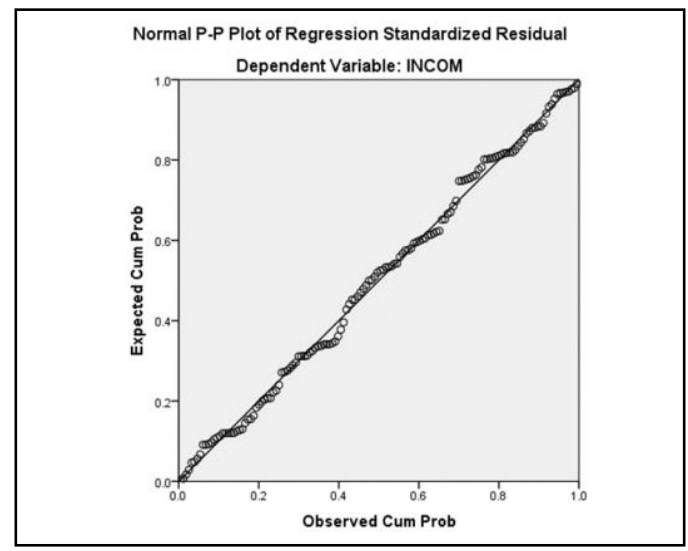

Figure 1. Homoscedasticity

\subsection{Mediation analysis}

Each path of the mediation hypothesis was analyzed by utilizing bootstrap method with 5000 samplings at $95 \%$ confidence interval. Table 1 illustrates the results of the analysis of path a, the direct effect of the predictor, mattering on the mediator, USA.

Table 1. Path a, the direct effect of the predictor on the mediator

\begin{tabular}{ccccccccccc}
\hline Coeff & $\mathrm{R}$ & $\mathrm{R}^{2}$ & $\mathrm{~F}$ & $\mathrm{df1}$ & $\mathrm{df} 2$ & $\mathrm{se}$ & $\mathrm{t}$ & $\mathrm{p}$ & $\mathrm{LLCI}^{1}$ & $\mathrm{ULCI}^{2}$ \\
\hline .23 & .23 & .05 & 19.75 & 1.00 & 368.00 & 4.50 & 12.74 & .000 & 48.48 & 66.18 \\
\hline${ }^{1}$ Lower level confident interval \\
${ }^{2}$ Upper level confident interval
\end{tabular}


Table 1 suggests that mattering significantly predicted USA, $b_{\mathrm{a}}=0.23, t \quad(368)=12.74, \mathrm{p}=.000$, Mattering as a model significantly predicted USA, $F(1,368)=19.75, \mathrm{p}=.000, R^{2}=.05$, explaining $5 \%$ of the variance in USA. Table 2 illustrates the results of the analysis of path $b$, the direct effect of the mediator, USA on the outcome, social comparison.

Table 2. Path $\mathrm{b}$, the direct effect of the mediator on the outcome

\begin{tabular}{lllllllllll}
\hline Coeff & $\mathrm{R}$ & $\mathrm{R}^{2}$ & $\mathrm{~F}$ & $\mathrm{df1}$ & $\mathrm{df} 2$ & $\mathrm{se}$ & $\mathrm{t}$ & $\mathrm{p}$ & LLCI $^{1}$ & $\mathrm{ULCI}^{2}$ \\
\hline-.19 & .34 & .12 & 47.90 & 1.00 & 368.00 & .03 & -6.92 & .000 & -.24 & -.13 \\
\hline
\end{tabular}

Based on Table 2, it can be seen that USA is a negative significant predictor of social comparison $b_{\mathrm{a}}=0.34, t(368)=-6.92, \mathrm{p}=.000$, social comparison as a model significantly predicted social comparison, $F(1,368)=47.90, \mathrm{p}=.000, R^{2}=.12$, explaining $12 \%$ of the variance in social comparison. Table 3 depicts the results of the analysis of path $\mathrm{c}$, the total effect of mattering on social comparison, without controlling for USA.

Table 3. Path c, the total effect of the predictor as a model on the outcome

\begin{tabular}{ccccccccccc}
\hline Coeff & $\mathrm{R}$ & $\mathrm{R}^{2}$ & $\mathrm{~F}$ & $\mathrm{df1}$ & $\mathrm{df} 2$ & $\mathrm{se}$ & $\mathrm{t}$ & $\mathrm{p}$ & $\mathrm{LLCI}^{1}$ & $\mathrm{ULCI}^{2}$ \\
\hline .10 & .38 & .14 & 31.04 & 2 & 367 & .03 & 3.56 & .00 & .044 & .15 \\
\hline${ }^{1}$ Lower level confident interval & & & & & & & \\
${ }^{2}$ Upper level confident interval
\end{tabular}

Table 3 suggests that without controlling for the mediator, mattering significantly predicted social comparison, $b_{\mathrm{a}}=0.10, t(367)=3.56, \mathrm{p}=.000$, Mattering as a model significantly predicted social comparison, $F(2,367)=31.04, \mathrm{p}=.000, R^{2}=.14$, explaining $14 \%$ of the variance in social comparison. Table 4 and Table 5 show the indirect effect of the predictor on the outcome variable.

Table 4. Path ab, the indirect effect of predictor on the outcome through the mediator

\begin{tabular}{|c|c|c|c|}
\hline Effect & BootSE $^{1}$ & BootLLCI $^{2}$ & BootULCI $^{3}$ \\
\hline-.05 & .01 & -.072 & -.027 \\
\hline
\end{tabular}

Table 4 indicates that UAS mediates the relationship between mattering and social comparison, because the upper and lower level of bootstrap confident interval are both negative. It shows that among the 5000 samplings conducted by the PROCESS Macro, none of them resulted in zero; which means that all the processes were significant. Table 5 shows whether USA fully or partially mediated the link between the predictor and the outcome variables.

Table 5. Path c', the direct effect of predictor on the outcome

\begin{tabular}{cccccc}
\hline Effect & $\mathrm{se}$ & $\mathrm{t}$ & $\mathrm{p}$ & $\mathrm{LLCI}^{1}$ & $\mathrm{ULCI}^{2}$ \\
\hline .10 & .03 & 3.56 & .00 & .04 & .15 \\
\hline${ }^{1}$ Lower level confident interval \\
${ }^{2}$ Upper level confident interval
\end{tabular}

Table 5 reveals that even after controlling for USA, the direct effect of mattering on social comparison was still significant. It means that USA partially mediates the link between the other two variables, and that mattering can be considered as a robust predictor of social comparison.

\subsection{Discussion}

The findings suggested that USA acted as a suppressing mediator in the relationship between mattering and social comparison, which showed that undergraduates with higher mattering will positively 
predict USA, and thus elicit lower social comparison. This result showed consistency with the concept explaining people experienced unconditional positive regard felt the basic acceptance and acknowledged by others [32]. Similarly with the current findings stated, being felt mattered to others will led them to accept themselves unconditionally, and thus tend to view themselves more objectively on their self-evaluation regardless being compared or critiqued by others, in which showed supportive findings according the social comparison theory [1].

Our results have shown consistency with past findings suggested that mattering is a significant positive predictor of USA [21], [29]. Past study has found that the sense of not mattering to others was a unique core vulnerability to other factors, where the unique predictive ability of mattering was found in the research [33]. Individuals who have adequate level of USA might still be at risk due to the core sense of not feeling valued and acknowledged by others. This showed that mattering played an important role in determining self-evaluation and comparative self-criticism [33]. This can be further elaborated by saying people who felt they mattered to others will be reflected by a positive self-view and acknowledged themselves as the way there were, thus elicited higher USA. Besides, another study found that undergraduates with high USA attributed success positive feedback as stable and internal, whereas attributed failure and negative feedback as unstable and external [34]. Following the current findings, it was shown that undergraduates with higher USA tend to evaluate themselves more objectively and less responsive reactivity towards opinion from others, thus leading lower tendency for social comparison. This explanation showed consistency with past studies mentioned earlier [8], [20], [27] thus strengthens the findings of this research.

On the other hand, it was also reported that there may be other associating factors affecting the relationship between mattering and social comparison. Past study suggested that participants with low mattering will perceived themselves not important to others as self-esteem would be influenced by their negative perceptions [35]. As this has found consistently with research mentioned earlier where USA and self-esteem are highly correlated despite a key distinction between the two constructs [8], this would have further explained that lowered self-esteem will also increase the risk of being vulnerable to subjective comparison with others. In accordance with some studies mentioned earlier, these studies suggested that the association between mattering and social comparison may have other possible mediators considering individual factors, self-esteem, perceived self-perception and relation to others [36], which may contribute a better understanding together with component of USA on the association. These studies may explain the underlying reason where mattering still predict social comparison when controlling for USA, where it also suggested that there will still be another direct link between mattering and social comparison after taking USA into consideration, thus resulting a partial mediation in the current findings.

It is interesting to note that mattering positively predicted social comparison when controlling for USA, despite finding out that USA has negatively predicted social comparison when controlling for mattering. It has been mentioned earlier that undergraduates aged between 18-25 years were in the mist of identity exploration, possibilities and instability [10], which could mean that they may be more vulnerable towards different perspectives and comparison among peers, thus their perception of own USA may also fluctuate during various encounter. Along their pathway on finding their identity, we can conclude from the results suggesting that social comparison still occurs among undergraduates-undergraduates who has high mattering may compare with others to maintain their self-concept, whereas undergraduates who has low mattering may compare with others to obtain feedback and opinion about themselves. When adding USA into the relationship in the current study, USA was found to be a negative predictor of social comparison, which could mean that the tendency of social comparison has decreased when USA was taken into consideration. This finding depicted that USA acted as an important role associating this relationship, where the tendency of social comparison was lowered down with the help of USA, especially when undergraduates were brought to attention in the current study.

Overall, although USA may not be the only factor that influence this correlation, but USA acted as an influential suppressing mediator in the relationship between mattering and social comparison. Results also showed that the stronger negative predictor of USA has reduced the beta value for mattering, resulting the total effect to be not significant. This again showed that USA acted as big role in this relationship, which was also supported by past study explaining that USA contributed one of the highest impacts on psychological well-being [37]. While showing strong association with self-esteem and self-worth which would be beneficial for treatment and remedy towards general public, may serve as a motivational strategy to improve own selfacceptance in relation to mattering and reducing the tendency of social comparison in long run [8].

\subsection{Limitations and improvements}

The study was conducted using self-reported questionnaire on online google form, there may be inaccurate perceptions due to perceived social desirability, subjective reporting biases may occur. A method of multi-agent reporting could be used in future studies to collect more objective and comprehensive data. 
Moreover, this study only examined the mediating effect of USA between mattering and social comparison, not exploring other interpersonal factors. In future research, researchers could examine the other mediating factors such as interpersonal relationship, self-esteem and individual perception of self to have a better understanding of the association. As for another improvement, future researchers might need to take consideration of participants' individual characteristic and background, for instance pre-testing participant's personality or self-perception before carrying out the study to obtain a more comprehensive viewpoint of the entire framework. This study cannot explain the causal relationship among variables, therefore similar research with different method (qualitative or quantitative experiment) is suggested for future studies.

\subsection{Contributions and implications}

Despite these limitations, the results of current study were encouraging and warrant additional research, which have brought more attention on USA, similarly with past studies stating that significant contribution was found in USA to predict mental health and well-being indicators [8]. This study may help to contribute to the theories that USA acting as an important role influencing the relationship between mattering and social comparison. The practical implication of this study is that this may apply into school setting acting as an intervention to improve student's well-being by reducing social comparison with others. For instance, workshops or talks can be carried out to improve their unconditional self-acceptance, which will help them to enhance self-concept and reduce unnecessary social comparison among peers.

\section{CONCLUSION}

This study was conducted to examine the mediating role of unconditional self-acceptance in mattering and social comparison among Malaysian undergraduate students. The result showed that USA only partially mediated the relationship between mattering and social comparison. The findings also highlighted the important role of USA in this association, as it could help in reducing the tendency of social comparison which may have detrimental effect on self. Future studies could also investigate on other factors associating this relationship, and thus able to further elaborate on how USA can improve one's self-concept.

\section{ACKNOWLEDGEMENTS}

This study is funded by the Internal Research Grant Scheme from HELP University \# 20-07-024.

\section{REFERENCES}

[1] L. Festinger, "A theory of social comparison processes," Human Relations, vol. 7, no. 2, pp. 117-140, 1954.

[2] Q.-Q. Liu, Z.-K. Zhou, X.-J. Yang, G.-F. Niu, Y. Tian and C.-Y. Fan, "Upward social comparison on social network sites and depressive symptoms: A moderated mediation model of self-esteem and optimism," Personality and Individual Differences, vol. 113, pp. 223-228, 2017.

[3] M. Tiggemann, S. Hayden, Z. Brown and J. Veldhuis, "The effect of Instagram "likes" on women's social comparison and body dissatisfaction," Body Image, vol. 26, pp. 90-97, 2018.

[4] D. A. De Vries and R. Kühne, "Facebook and self-perception: Individual susceptibility to negative social comparison on Facebook," Personality and Individual Differences, vol. 86, pp. 217-221, 2015.

[5] K. D. Prihadi, E. S. Lim, E. Sim and K. Chong, "Mattering and Life Satisfaction among the Quarantined Adults in Malaysia during the Covid-19 Pandemic," International Journal of Public Health Science (IJPHS), vol. 10, no. 1, 2020.

[6] S. H. Carson and E. J. Langer, "Mindfulness and self-acceptance," Journal of Rational-Emotive and CognitiveBehavior Therapy, vol. 24, no. 1, pp. 29-43, 2006.

[7] K. Prihadi, Y. L. Hui, M. J. Chua and C. K. W. Chang, "Cyber-victimization and perceived depression: Serial mediation of self-esteem and learned-helplessness," International Journal of Evaluation and Research in Education (IJERE), vol. 9, no. 1, pp. 563-574, 2019.

[8] J. M. Chamberlain and D. A. Haaga, "Unconditional self-acceptance and psychological health," Journal of Rational-Emotive and Cognitive-Behavior Therapy, vol. 19, no. 3, pp. 163-176, 2001a.

[9] K. D. Prihadi, C. Y. Wong, E. Y. Chong and K. Y. Chong, "Suicidal Thoughts among University Students in Malaysia and Indonesia: The Role of Mattering, State Self-Esteem and Depression Level," International Journal of Evaluation and Research in Education (IJERE), vol. 9, no. 3, pp. 494-502, 2020.

[10] J. J. Arnett, "Emerging adulthood: A theory of development from the late teens through the twenties," American Psychologist, vol. 55, no. 5, p. 469-480, 2000.

[11] S. Casale and G. L. Flett, "Interpersonally-based fears during the covid-19 pandemic: Reflections on the fear of missing out and the fear of not mattering constructs," Clinical Neuropsychiatry, vol. 17, no. 2, p. 88-93, 2020.

[12] K. D. Prihadi, E. S. Lim, K. Chan, S. M. Lee and A. Ridwan, "Efficacy of Working from Home among Urban Professionals in Malaysia during the Pandemic: The Robust Predictive Role of Mattering," International Journal of Public Health Science (IJPHS), vol. 10, no. 1, 2020. 
[13] M. F. Davies, "Irritational beliefs and unconditional self-acceptance. III. The relative importance of different types of irrational belief," Journal of Rational-Emotive \& Cognitive-Behaviour Therapy, vol. 26, pp. 102-118, 2008.

[14] H. J. Yu, "The mediating effects of college student's internalized shame and unconditional self-acceptance in the influence of socially prescribed perfectionism on interpersonal competence," The Korean Data \& Information Science Society, vol. 30, no. 6, pp. 1350-1373, 2019.

[15] B. L. Thompson and J. A. Waltz, "Mindfulness, self-esteem, and unconditional self-acceptance," Journal of Rational-Emotive \& Cognitive-Behavior Therapy, vol. 26, no. 2, pp. 119-126, 2008.

[16] E. A. Vogel, J. P. Rose, B. M. Okdie, K. Eckles and B. Franz, "Who compares and despairs? The effect of social comparison orientation on social media use and its outcomes," Personality and Individual Differences, vol. 86, pp. 249-256, 2015.

[17] J. B. White, E. J. Langer, L. Yariv and J. C. Welch, "Frequent social comparisons and destructive emotions and behaviors: The dark side of social comparisons," Journal of Adult Development, vol. 13, no. 1, pp. 36-44, 2006.

[18] A. S. Alderson and T. Katz-Gerro, "Compared to whom? Inequality, social comparison, and happiness in the United States," Social Forces, vol. 95, no. 1, pp. 25-54, 2016.

[19] K. Burleson, C. W. Leach and D. M. Harrington, "Upward social comparison and self-concept: Inspiration and inferiority among art students in an advanced programme," British Journal of Social Psychology, vol. 1, pp. 109-123, 2005.

[20] A. Ellis, "Psychotherapy and the value of a human being," in A. Ellis and R. Grieger, Eds., Handbook of rationalemotive therapy, New York, Springer, 1977, pp. 99-112.

[21] G. Flett, The psychology of mattering: Understanding the human need to be significant. United Kingdom: Academic Press, 2018.

[22] G. Elliott, S. Kao and A. M. Grant, "Mattering: Empirical validation of a social-psychological concept," Self and Identity, vol. 4, pp. 339-354, 2004.

[23] M. K. France and S. J. Finney, "What matters in the measurement of mattering? A construct validity study," Measurement and Evaluation in Counseling and Development, vol. 42, no. 2, pp. 104-120, 2009.

[24] M. Rosenberg, "Self-concept and psychological well-being in adolescence," in R. Leahy, Ed., The development of the self, New York: Academic Press, 1985, pp. 205-246.

[25] F. X. Gibbons and B. P. Buunk, "Individual differences in social comparison: development of a scale of social comparison orientation," J. Pers. Soc. Psychol., vol. 76, p. 129-142, 1999.

[26] J. M. Chamberlain and D. A. Haaga, "Unconditional self-acceptance and responses to negative feedback," Journal of Rational-Emotive and Cognitive-Behavior Therapy, vol. 19, no. 3, pp. 177-189, 2001b.

[27] H. Kim, M. J. Callan, A. I. Gheorghiu and W. J. Matthews, "Social comparison, personal relative deprivation, and materialism," British Journal of Social Psychology, vol. 56, no. 2, pp. 373-392, 2017.

[28] P. P. Sim and K. Prihadi, "They Logged-in, Compared, and Satisfied: Serial Mediation of Mattering and State Selfesteem on the Link between Social Comparison and Life Satisfaction," International Journal of Public Health Science (IJPHS), vol. 9, no. 3, pp. 245-254, 2020.

[29] A. W. Leschied, D. H. Saklofske and G. L. Flett, Handbook of school-based mental health promotion. Cham, Switzerland: Springer International Publishing, 2018.

[30] H. Taniguchi, "Interpersonal Mattering in Friendship as a Predictor of Happiness in Japan: The Case of Tokyoites," Journal of Happiness Studies, vol. 16, no. 6, pp. 1475-1491, 2015.

[31] R. V. Krejcie and D. W. Morgan, "Determining sample size for research activities," Educational and Psychological Measurement, vol. 30, no. 3, pp. 607-610, 1970.

[32] C. R. Rogers, Client-centered therapy. Boston: Houghton Mifflin, 1951.

[33] G. L. Flett, R. Burdo and T. Nepon, "Mattering, insecure attachment, rumination, and self-criticism in distress among university students," International Journal of Mental Health and Addiction, pp. 1-14, 2020, doi: 10.1007/s11469-020-00225-z.

[34] S. Popov, J. Radanović and M. Biro, "Unconditional self-acceptance and mental health in ego-provoking experimental context,” Suvremena Psihologija, vol. 19, no. 1, pp. 71-80, 2016.

[35] M. Cha, "The mediation effect of mattering and self-esteem in the relationship between socially prescribed perfectionism and depression: Based on the social disconnection model," Personality and Individual Differences, vol. 88, pp. 148-159, 2016.

[36] H. Taniguchi, "Interpersonal mattering in friendship as a predictor of happiness in Japan: The case of Tokyoites," Journal of Happiness Studies, vol. 16, no. 6, pp. 1475-1491, 2015.

[37] T. Y. Bingöl and M. V. Batık, "Unconditional self-acceptance and perfectionistic cognitions as predictors of psychological well-being," Journal of Education and Training Studies, vol. 7, no. 1, pp. 67-75, 2018. 